\title{
A Thank-You, Long Overdue
}

In 2005, I attended my first NACIS Annual Meeting. My attendance was as much from a desire to see Salt Lake City, Utah and hear the Salt Lake Tabernacle Organ, as it was to meet with others interested in cartography. And, too, I had the rather base desire to promote my book, Cartographies of Disease, then recently published.

What I did not expect was that the tone and tenor of the meeting and its conversations would set my research agen$\mathrm{da}$ for the next twelve years. While reading the proofs for the book whose origins were in that meeting, it seemed time to tender my thanks to the members of NACIS.

In those days, I was co-teaching Spatial Data Analysis for GIS at the University of British Columbia and working in gerontology and medical ethics, my other lines of research and work. When ethics became a subject in some of the Salt Lake City discussions I was . . . intrigued. It had not occurred to me that questions about propriety would be a subject of interest to professional mapmakers. Then, during the Map-Off, a studio-like critique session, I used ethics as a way of critiquing the entries. That lead to several lengthy discussions with members about morals, ethics, and what they mean for working cartographers.

After the meetings, as well as a year of consultation and thinking, I published an article, "False Truths," in Cartographic Perspectives (Koch 2006). Its intent was to create a way to talk in a non-academic, practical way about the issues that members had raised about ethics and appropriateness. That basic program and its ethical set-up became a centerpiece of my teaching, thinking, and finally, writing over the next decade. The end result is a new book: Ethics in Everyday Life: Mapping Moral Stress, Distress, and Injury (Koch 2017).

What was clear to me from the start was that some NACIS members faced situations that were troubling. What should a mapmaker do when an assignment seemed biased, limited, or somehow antithetical to their own sense of right and truth? How can members reconcile their "professional" duties - make the maps people request-and their personal duty as citizens? This isn't a new question or one unique to the cartographic community. The literature calls it "moral stress," and it is found in many parts of society. Today it's central to discussions of post-traumatic stress in first responders, military, and police. It's also raised frequently in discussion of distress among medical workers-mostly doctors and nurses-whose sense of personal "agency" is restricted by professional directives (Jennings, Wert, and Morrissey 2016).

What I did not know in 2005 was the degree to which the concerns raised by NACIS members might (or might not) be the same as those raised by members of those seemingly more critical, life-and-death professions. "False Truths" gave me the tools with which to ask this question not only in cartography and geography, but across a range of professions. It turned out that the dilemmas of some NACIS members were the same as those faced not only by first-responders but also by graphic artists, journalists, statisticians, and others.

Along the way, I made a fundamental and, to me, surprising discovery: maps are a terrific medium to empower questions about ethics, morality, and how we act as individuals and citizens in the world. The old debate between "objective" and "persuasive" mapping falls by the wayside when one realizes that maps present our ideas about the world and what we think important in it.

Whatever the subject, data are gathered and then presented at one or another scale of address to prove (or disprove) a thesis or idea. Maps are therefore no more or less objective than the ideas behind the collection and organization of the data. This isn't a new idea, of course. Denis Wood argued something similar in his Power of Maps, for example (Wood 1992). But in thinking about both mapping 
and ethics, what quickly became clear to me was that the ideas that dictate the form of the map carry implicit and sometimes explicit ethical arguments. No wonder NACIS members are sometimes queasy about an assignment when they are ambivalent about the nature of the work they are asked to graphically summarize.

The other thing about maps that was critical to this exploration is that they are always ecologies, always about things together rather than about this or that dataset alone. Mapmakers take a data table's rows and fashion them into event classes that are then posted in a geography (political jurisdictions, streets and roads, streams and rivers, etc.) that argues a relationship between these event classes and the environment at one or another scale. Often, two event classes are joined in an attempt to show causal effects (poverty and resulting disease, for example).

So, in examining this or that map from an ethical perspective, one sees ethical ideas for which data have been collected and presented based on a single point of view. This means we can use the map to interrogate the ideas behind the map and, sometimes, the data that were chosen to support a singular point of view. A map, in short, doesn't just show "x," but places " $x$ " in a geography based on ideas about the good or bad, the right or wrong of a thing. Ethics, in short.

Consider, for example, John Snow's famous 1855 map of the ferocious cholera outbreak in his Soho neighborhood of London (Snow 1855). It is "scientific" in its promise of objective data. It "shows" cholera incidence during the late summer of 1854. But: what lies behind and beneath the mapping? It presented public data collected by the Registrar General to identify the extent and effect of cholera during the first weeks of the outbreak. That dataset was collected as part of the government's obligation to its citizens to protect their health and in doing so to identify threats to the public good.

Snow's map argued that cholera is exclusively waterborne and not airborne. That was the idea he was testing, and so in the map he identified a single central water sourcethe Broad Street pump-as the likely origin of the outbreak. Why did he make this argument? Well, first, Snow was a physician who believed deeply in medicine as a Hippocratic, environmental discipline, and in the role of the environment in the health of peoples. His science was not disinterested but bound up in an ethical obligation to

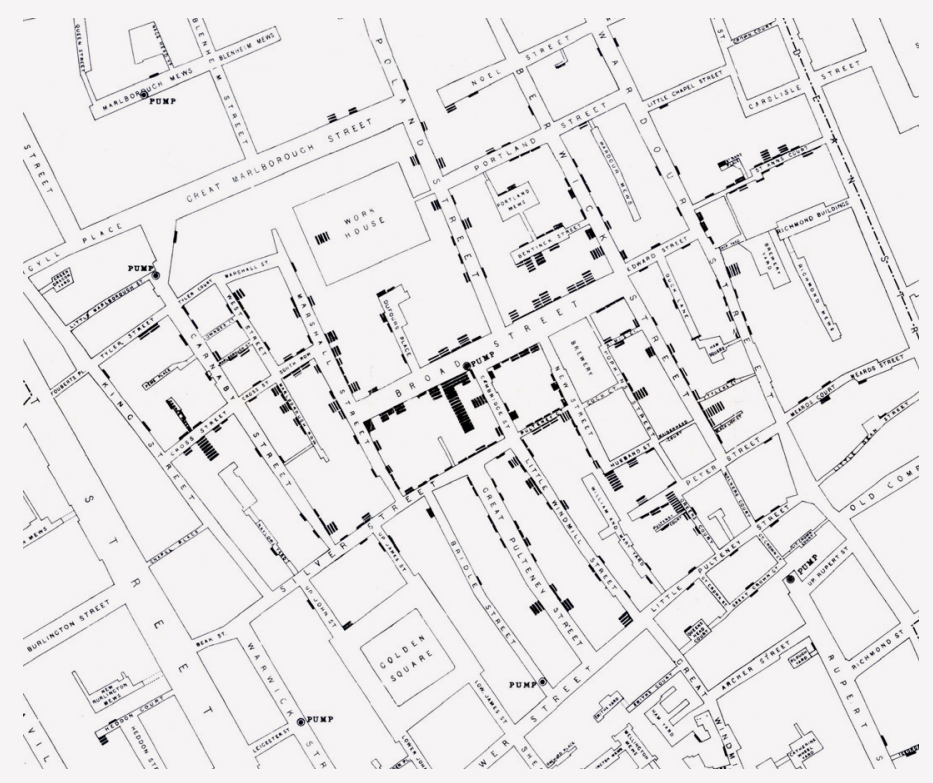

Detail of Snow's cholera map.

care, and for the social address of unhealthy environmental dangers.

But for Snow there was also a personal agenda. Yes, as a medical scientist he wanted to identify the specific cause of the disease that was ravaging his neighborhood, his nation, and, indeed, western countries generally. There is nothing wrong with ambition. But as his writings repeatedly demonstrated, Snow's fight to tame cholera owed to his past. In the first cholera pandemic he was an apprentice apothecary caring for mining patients near Newcastle-Upon-Tyne (Vinten-Johansen et al. 2003). He watched them die and was traumatized by his inability to help them. So in seeking a simple source of the disease he sought to address what had been medicine's (and thus his) limits in treating people who came to him for health.

So the famous map of the Broad Street outbreak carries behind it a series of ideas. Its central thesis is, indeed, that cholera is waterborne and not airborne. But it-and other maps of the outbreak-also carried a commitment by government and by medical professionals to the health and welfare of citizens. That's why the data were collected and made freely available. And in searching for the causes of cholera, Snow and other physicians held the idea that their duty was to identify the source of illnesses as well as to find the best treatments for their patients.

But because Snow was arguing a narrow thesis-cholera as a solely waterborne disease-his map did not include 
the sewer lines and former plague areas that others believed were implicated in an airborne disease. So yes, the map's data were objective, but they were limited by Snow's thesis. Other maps, arguing other origin theories, were different. But behind all of these was the central ethical argument that both government officials and civil authorities (for example the London Sewer Commission; Cooper 1854), as well as physicians, were responsible for the health and welfare of peoples.

How do we know all this? Well, one can deduce it from the map and one can confirm it in the writings of Snow and his contemporaries.

\section{MAPS ELSEWHERE}

When one starts looking at a map's underlying ideas, at its organizing thesis, one begins to see these things everywhere. Almost any map, or for that matter any graphic, can be similarly interrogated for both its meaning and its ideas of good and bad, right and wrong, and the ethics and the morals that support them. And so from the limited story of "False Truths" and the questions of NACIS members, I began to look at maps in newspapers and science journals as not simply a geographic mapmaker but also as an ethicist. Why not? They are frequent publishers of maps.

In looking at maps as they are used I began to ask not only about the ethics of the map but the means by which a map may hide its truths. In this, I was fortunate. Alexandra Enders, then at the University of Montana, sent me a map of poverty in the United States by county. It wasn't a particularly radical map; indeed, government websites permit the automatic generation of similar maps today. But, looking at the map, I wondered why I felt unmoved by it and by the legend's statement that 12.5 percent of all Americans lived in circumstances that, by government definition, limited their ability to obtain daily necessities.

Well, what is the proper unit for discussions like this? Is it states or counties or something else? And in asking about where poverty is, we can also ask what does poverty mean and why do we care? Is this about nationalism-the promise of a "more perfect union" among equal peoples-or is a map of poverty simply the tallying of winners and losers in a capitalist scheme where nobody owes much to anybody else?
The poverty maps I reviewed open the door to questions about maps as a tool to look at the ethics of civil programs and policies in a range of subject areas. These included inequalities in educational funding in the United States, accessibility in public transit systems, and the ethics that supposedly direct United States graft organ transplant programs.

These were not new subjects to me. But what the NACIS meeting did was force me to review my previous work and reinterpret it in the context of ethics and moralities, personal and public. And so, in doing so, I was able to extend the work I had previously done.

\section{CONCLUSION}

Professional meetings serve many functions. Besides the obvious, they're convenient ways to see new places, visit friends, and, of course, advance one's career. But we sometimes overlook the truly important boon of a good conference: the opportunity to think new thoughts and think differently about the things we already do competently. This is just a belated thanks to all those members who helped me do exactly that back in 2005, when I opened my big mouth and thought I understood the issues that were perplexing to others.

So ... thanks.

Tom Koch is adjunct professor of (medical) geography at the University of British Columbia. His sixteenth book, Ethics in Everyday Life: Mapping Moral Stress, Distress, and Injury will be available in late 2017 from MIT Press.

\section{REFERENCES}

Cooper, Edmund. 1854. Report on an Enquiry and Examination into the State of the Drainage of the Homes Situate in that part of the Parish of St. James, Westminster. 22 Sept. Metropolitan Commission of Sewers 478/21. London Metropolitan Archives, 1, 2, 6.

Jennings, Bruce, Frederick J. Wertz, and Mary Beth Morrissey. 2016. "Nudging for Health and the Predicament of Agency: The Relational Ecology of Autonomy and Care," Journal of Theoretical and Philosophical Psychology 36 (2): 81-99. doi: 10.1037/ teo0000041. 
Koch, Tom. 2017. Ethics in Everyday Life: Mapping Moral Stress, Distress, and Injury. Cambridge, MA: MIT Press.

2006. "False Truths: Ethics and Mapping as a Profession.” Cartographic Perspectives 54: 4-15. doi: 10.14714/CP54.343.

Snow, John. 1855. On the Mode of Communication of Cholera. London: Churchill.
Wood, Denis. 1992. The Power of Maps. New York: Guilford Press.

Vinten-Johansen, Peter, Howard Brody, Nigel Paneth, Stephen Rachman, and Michael Rip. 2003. Cholera, Chloroform, and the Science of Medicine: A Life of John Snow. New York: Oxford University Press. 